\title{
Impact loading and modelling a multilayer aluminium corrugated/fin core: The effect of the insertion of imperfect fin layers
}

\author{
Mustafa Sarıkaya | Alper Taşdemirci | Mustafa Güden (D)
}

Dynamic Testing and Modeling Laboratory and Department of Mechanical Engineering, Izmir Institute of Technology, Izmir, Turkey

\section{Correspondence}

Mustafa Güden, Dynamic Testing and Modeling Laboratory and Department of Mechanical Engineering, Izmir Institute of Technology, Gülbahçe Köyü, Urla, Izmir, Turkey.

Email: mustafaguden@iyte.edu.tr

\begin{abstract}
The quasi-static compression $(0.0048 \mathrm{~m} / \mathrm{s})$ and Taylor-like impact $(135,150$, and $200 \mathrm{~m} / \mathrm{s}$ ) loading of a multilayer $1050 \mathrm{H} 14$ aluminium corrugated core were investigated both experimentally and numerically in LS-DYNA using the perfect and imperfect sample models. In the imperfect sample models, one or two layers of corrugated fin structure were replaced by the fin layers made of bent-type cell walls. The localised deformation in the quasi-static imperfect models of cylindrical sample started at the imperfect layers, the same as the tests, and the layers were compressed until about the densification strain in a step-wise fashion. The localised deformation in the perfect models, however, started at the layers at and near the top and bottom of the test sample. In the shock mode, the sample crushed sequentially starting at the impact end layer regardless the perfect or imperfect sample models were used. Furthermore, the perfect and imperfect models resulted in nearly the same initial crushing stresses in the shock mode. The layer strain histories revealed a velocity-dependent layer densification strain. Both model types, the imperfect and perfect, well approximated the stress-time histories and layer deformations of the shock mode. The rigid perfectly plastic locking model based on the numerically determined densification strains also showed well agreements with the experimental and numerical plateau stresses of the shock mode.
\end{abstract}

\section{KEYWORDS}

cellular structure, impact loading, imperfection, modelling, shock stress

\section{1 | INTRODUCTION}

Metallic cellular structures deform, after a critical velocity, by forming sequential, planar crush bands starting/propagating at the impact end,${ }^{[1,2]}$ known as shock deformation mode. The shock mode of deformation was previously observed in the impact testing wood, ${ }^{[3,4]}$ urethane foam, ${ }^{[5]}$ aluminium foam, ${ }^{[1,6]}$ aluminium honeycomb, ${ }^{[2]}$ and multilayer corrugated structures. ${ }^{[7]}$ The shock mode is characterised by an impact-end stress far greater than the distal end stress, and the difference in-between increases as the impact velocity increases. The shock deformation of aluminium closed cell foams ${ }^{[6,8-17]}$ and honeycombs ${ }^{[2,18-24]}$ has been widely investigated both experimentally and numerically. An extensive review article on the dynamic compression behaviour cellular materials has also been recently published. ${ }^{[25]}$ The results of these studies have clearly identified three distinct deformation modes at increasing velocities. At quasi-static 
velocities, crush bands (localised deformation) form randomly, starting most likely at the weakest region of sample and progressing discretely to the uncrushed regions. Because the impact-end and distal end stresses are nearly the same, it is referred to as "quasi-static homogenous mode." ${ }^{[26]}$ The homogenous deformation was previously identified in regular and irregular honeycombs as X-shaped shear bands, ${ }^{[23]}$ in Voronoi honeycombs ${ }^{[27]}$ and in corrugated layered structure. ${ }^{[7]}$ At intermediate velocities, the deformation is considered as the "transition mode" as the layer crushing is concentrated at the impact-end. The strain distribution of crush bands in the transition mode is wider, and the strain does not reach the densification strain. ${ }^{[26]}$ At high velocities, a shock mode emerges.

The quasi-static and dynamic experimental and numerical studies on the metallic cellular structures have been noted to be mostly on aluminium open and closed cell foams and honeycomb structures as they have found wider applications. ${ }^{[25]}$ In parallel with this, the effects of imperfections on the crushing behaviour of aluminium foams ${ }^{[28,29]}$ and honeycombs ${ }^{[30,31]}$ have been investigated numerically. The effect of varying density and cell wall thickness and cell size on the dynamic response of these structures was also investigated numerically. ${ }^{[10,30,32,33]}$ On the other side, there have been only few recent studies on the dynamic behavior of multilayered corrugated structures. The low $(9 \mathrm{~m} / \mathrm{s})$ and high $(38 \mathrm{~m} / \mathrm{s})$ impact velocity deformation behavior of a graded multilayer 1060-O Al corrugated core has been recently investigated. ${ }^{[34]}$ Although no effect of grading was reported for low velocity impact tests due to the quasi-static equilibrium, the different gradient profiles exhibited different dynamic deformation response. A broad design criterion of inserting the weakest layer near the protected structure and the hardest layer near the impacted end of the graded sandwich was proposed in the same study. In another study, the strength enhancements of both single and multilayer 1060-O Al corrugated core sandwiches at increasing impact velocities were reported, although 1060-0 $\mathrm{Al}$ was not rate sensitive. ${ }^{[35]}$ This was attributed to micro inertia. The underwater impulsive loading behavior of an aluminum sandwich structure with the trapezoidal corrugated core has been recently investigated both experimentally and numerically, and it was shown that the corrugated sandwich plates suffered significantly smaller rear face deflection than solid plates of similar mass per area in air-backed condition. ${ }^{[36]}$ The effect of polymer foam filling on the blast performance of corrugated steel core sandwich panels was determined by air blast experiments. ${ }^{[37]}$ It was shown that foam filling affected the buckling mode of core. Few studies on the modelling static and dynamic deformation of corrugated sandwiches with single and double-layer have also been published, such as refs. ${ }^{[38,39]}$ Nevertheless, the effect of imperfections particularly on the shock mode of deformation multilayer corrugated structures at increasing impact velocities has not been fully explored. The aim of the present study was to investigate the effect of the insertion of imperfect layers on the shock mode of deformation of a multilayer 1050 H14 aluminium corrugated sandwich core. The investigated sandwich core was made of corrugated fin layers and previously shown to exhibit repeatable responses to mechanical forces under compression at low and high velocities. ${ }^{[7,40,41]}$ The quasistatic compression tests were performed at $0.0048 \mathrm{~m} / \mathrm{s}$, and the impact tests (Taylor-like impact) were performed at 135, 150, and $200 \mathrm{~m} / \mathrm{s}$. Three-dimensional finite element models of the tested samples were developed in LS-DYNA at the same velocities with the tests. Four models of the core samples, two perfect and two imperfect models, were developed. The validities of the implemented models were discussed along with the deformation velocity, high-speed camera records, and stress-time and layer strain-time histories. The effects of imperfect layers on the crushing stress, layer strains, and layer crushing behaviour were then determined at both quasi-static and impact velocities. Finally, the resultant impact-end stresses of impact tests and models were then compared with the stresses of the rigid perfectly plastic locking (r-p-p-l) model developed by Reid and Peng. ${ }^{[3]}$

\section{2 | RIGID PERFECTLY PLASTIC LOCKING MODEL}

The impact of a cellular material with a backing mass of $M$ to a rigid wall with an initial velocity of $v_{o}$ induces two distinct deformation regions: the crushed and densified region with a stress of $\sigma^{*}$ (initial crushing stress) and the elastically deformed region with a stress of $\sigma_{p}$ (plateaus stress) as seen in Figure 1a,b. In the same figure, $u$ is the displacement, $h$ is the length of the densified region, $x$ is the uncrushed length, $x_{o}$ is the initial length of the crushed region, $\rho$ is the density of the crushed region, $\rho_{o}$ is the initial density, $l_{o}$ is the initial length, $\varepsilon_{d}$ is the densification strain, $u_{s}$ is the particle velocity, $v_{o}$ is the initial velocity, and $v$ is the velocity. The relation between initial density and the density of crushed section is the following:

$$
\rho_{o}=\rho\left(1-\varepsilon_{d}\right)
$$




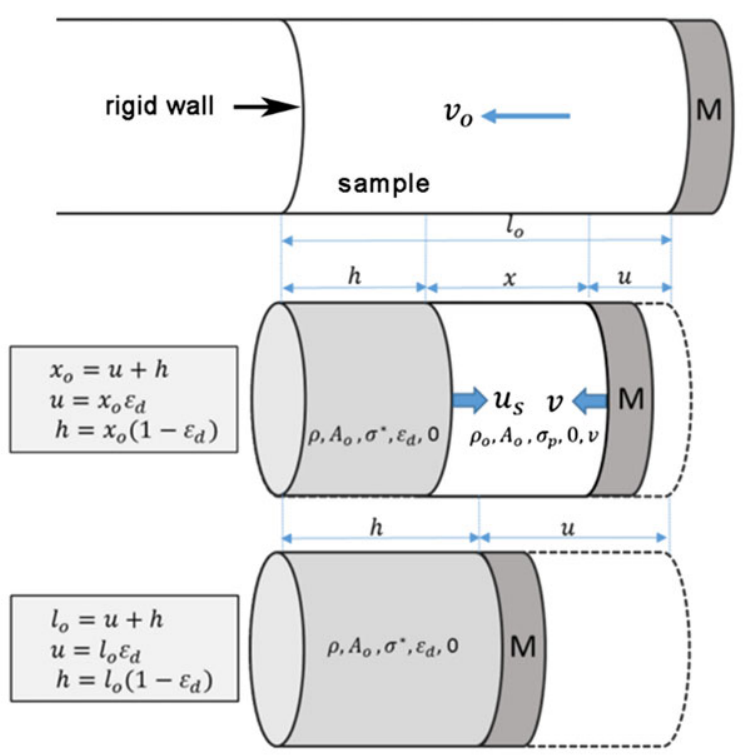

(a)

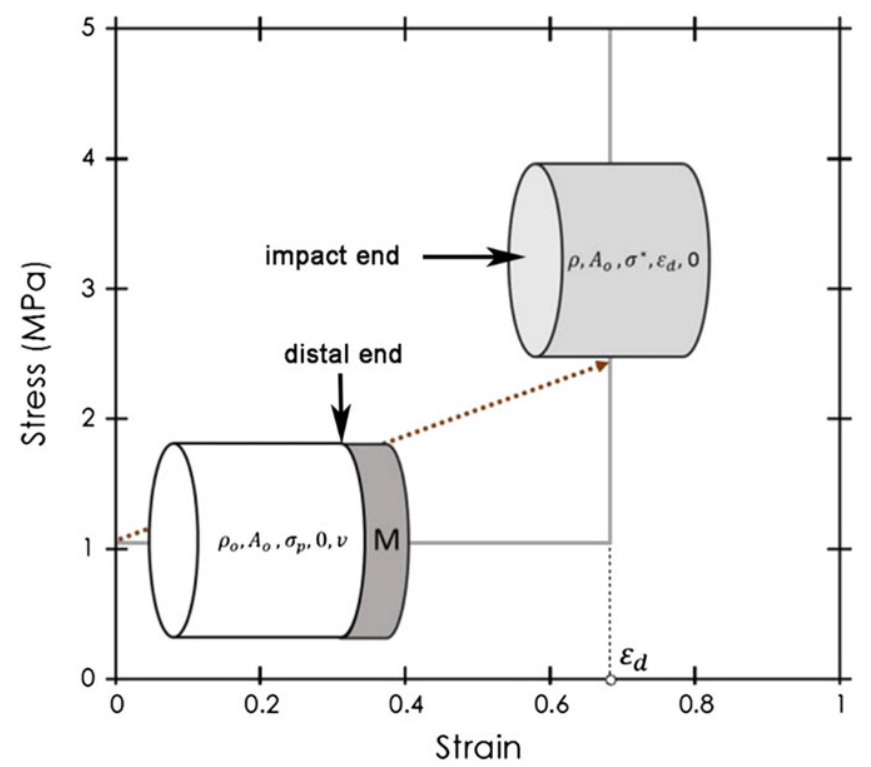

(b)

FIGURE 1 (a) The schematic of the impact of a cellular structure to a fixed wall schematic and (b) the rigid perfectly plastic locking model stress-strain behaviour and the crushed and uncrushed part of the cellular sample

Applying mass and momentum conservations between crushed and uncrushed section and the Newton's second rule to the uncrushed section results in particle velocity and crushing stress as follows:

$$
u_{s}=\frac{\left(1-\varepsilon_{d}\right)}{\varepsilon_{d}} v^{2}
$$

and

$$
\sigma^{*}=\sigma_{p}+\frac{\rho_{o}}{\varepsilon_{d}} v^{2}
$$

Applying Newton's second rule to the uncrushed section results in the time $(t)$ dependent velocity of the sample as follows ${ }^{[3]}$ : 


$$
v(t)=\sqrt{v_{o}^{2}+\frac{2 \sigma_{p} \varepsilon_{d}}{\rho_{o}} \ln \left(1-\frac{\rho_{o} A_{o} u}{M^{*} \varepsilon_{d}}\right)},
$$

where $M^{*}=M+\rho_{o} A_{o} l_{o}$. Inserting Equation (4) into Equation (3) gives a crushing stress as function of the time as follows ${ }^{[3]}$ :

$$
\sigma^{*}(t)=\sigma_{p}+\frac{\rho_{o}}{\varepsilon_{d}}\left[v_{o}^{2}+\frac{2 \sigma_{p} \varepsilon_{d}}{\rho_{o}} \ln \left(1-\frac{\rho_{o} A_{o} u}{M^{*} \varepsilon_{d}}\right)\right]
$$

The material completely densifies when $u=l_{o} \varepsilon_{d}$ and $x$ and $\dot{x}=0$. Then, the critical velocity for densification $\left(v^{\prime}\right)$ is determined as follows ${ }^{[3]}$ :

$$
v^{\prime}=\sqrt{\frac{2 \sigma_{p} \varepsilon_{d}}{\rho_{o}} \ln \left(1+\frac{m_{F}}{M}\right)},
$$

where $m_{F}$ is the mass of cellular material. When $M=0, v^{\prime}$ is infinity, implying that the cellular test specimen will not densify without backing mass in a Taylor-like impact test.

\section{3 | MULTILAYER CORRUGATED CORE AND TESTS}

The multilayer sandwich core was made of $1050 \mathrm{H} 14 \mathrm{Al}$ trapezoidal zig-zag corrugated 15-fin layer as seen in Figure 2a. The height, width, length, and thickness of a unit fin are sequentially $3.20,1.60,2.40$, and $0.170 \mathrm{~mm}$, respectively (Figure 2b). The fin layers were assembled through a brazing process using a $4343 \mathrm{Al}$ filler ( $7 \mathrm{wt} \%)$. The details of fin layers processing are given elsewhere. ${ }^{[42]}$ The fin layers were constructed in $0 / 90^{\circ}$ configuration with a 1 -mm-thick $1050 \mathrm{H} 14$ face sheet at both front and back faces. The samples for the quasi-static and dynamic tests were machined by an electro-discharge machine in 19.40-mm diameter and 48-mm height (Figure 3a). The samples had a density of $326 \mathrm{~kg} / \mathrm{m}^{3}$ without face sheets. The samples were tested without face sheets in the quasi-static compression tests, whereas the impact test samples had a face sheet at the rear/distal end. Fin wall damages/imperfections occur after the electro-discharge machining. The fin walls at the outer surface of the sample shown in Figure 3a are significantly bent. The bent fin walls are shown by arrows in the magnified outer surface image of the sample shown in Figure 3 b). As will be explained in the modelling section, a bending-type imperfection was introduced to the fin layers in order
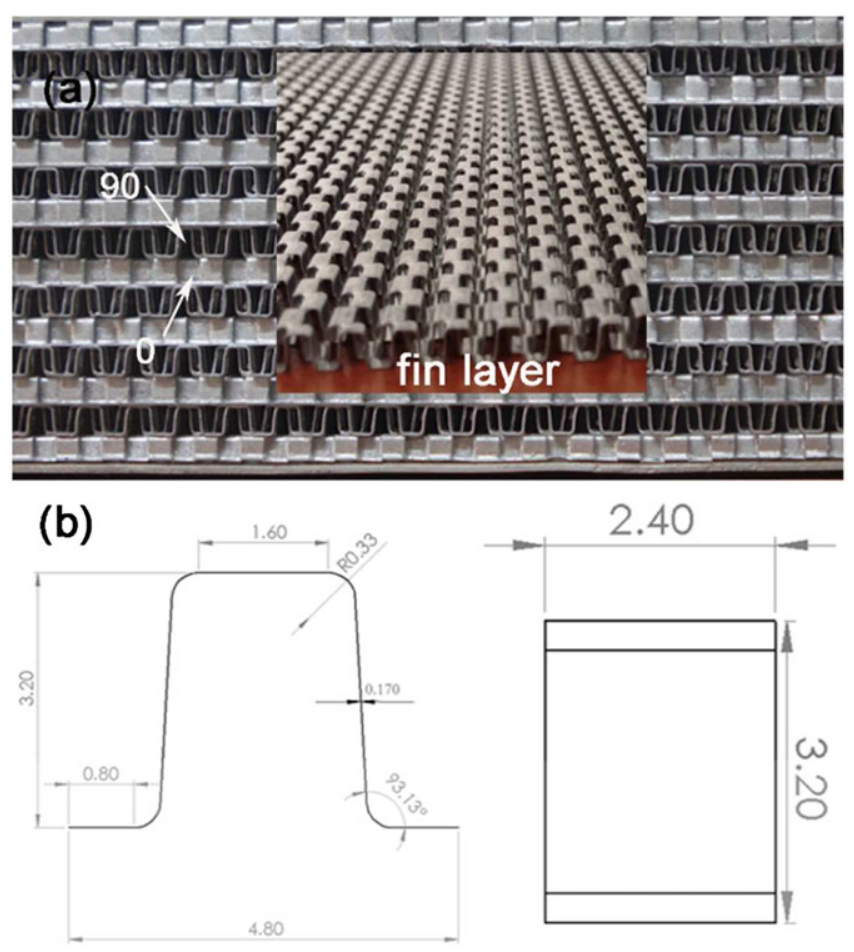

FIGURE 2 (a) Multilayer corrugated core and a fin layer and (b) fin geometrical sizes 

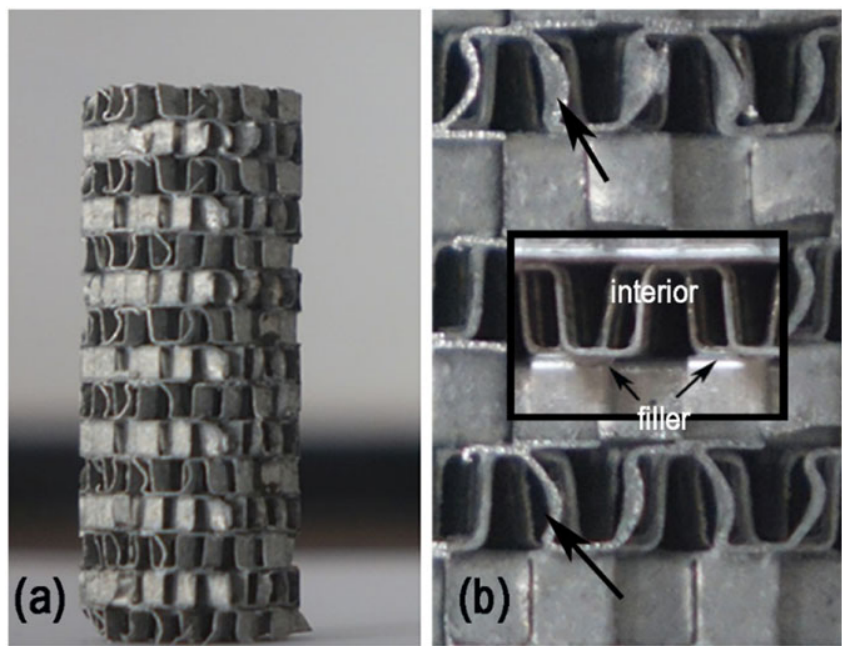

FIGURE 3 (a) Test sample in 19.40-mm diameter and in 48-mm height and (b) outer surface of a machined test sample with bent-fin walls (black arrows) and interior cell walls showing filler accumulation at the layer contacts

to simulate the effect of imperfections on the crushing behaviour. Another imperfection is the filler material accumulation at the layer contact regions as shown in the inset of Figure 3b. This makes the contact regions relatively thicker and hence may affect the densification strain.

The quasi-static compression tests were performed at $0.0048 \mathrm{~m} / \mathrm{s}$, corresponding to the nominal strain rate of $0.1 \mathrm{~s}^{-1}$. In the impact tests, the cylindrical corrugated test samples were directly impinged upon the end of the incident bar of an Inconel 718 Split Hopkinson Pressure Bar (SHPB) set-up with an initial velocity as schematically shown in Figure 4. The stress in the sample is calculated:

$$
\sigma_{S}(t)=\frac{A_{b} E \varepsilon_{I}}{A_{S}}
$$

where $\varepsilon_{I}$ is the strain on the incident bar, $A_{b}$ and $A_{s}$ are the cross-sectional areas of bar and sample, respectively, and $E$ is the elastic modulus of bar. The strain on the bar was recorded by means of two full-bridge strain gages mounted $300 \mathrm{~mm}$ (front strain gage) and 1,110 mm (back strain gage) away from the impact end in conjunction with an amplifier and oscilloscope as shown in Figure 4. The incident bar had a diameter of $19.40 \mathrm{~mm}$, the same as the sample.

FIGURE 4 Schematic of Taylor-like
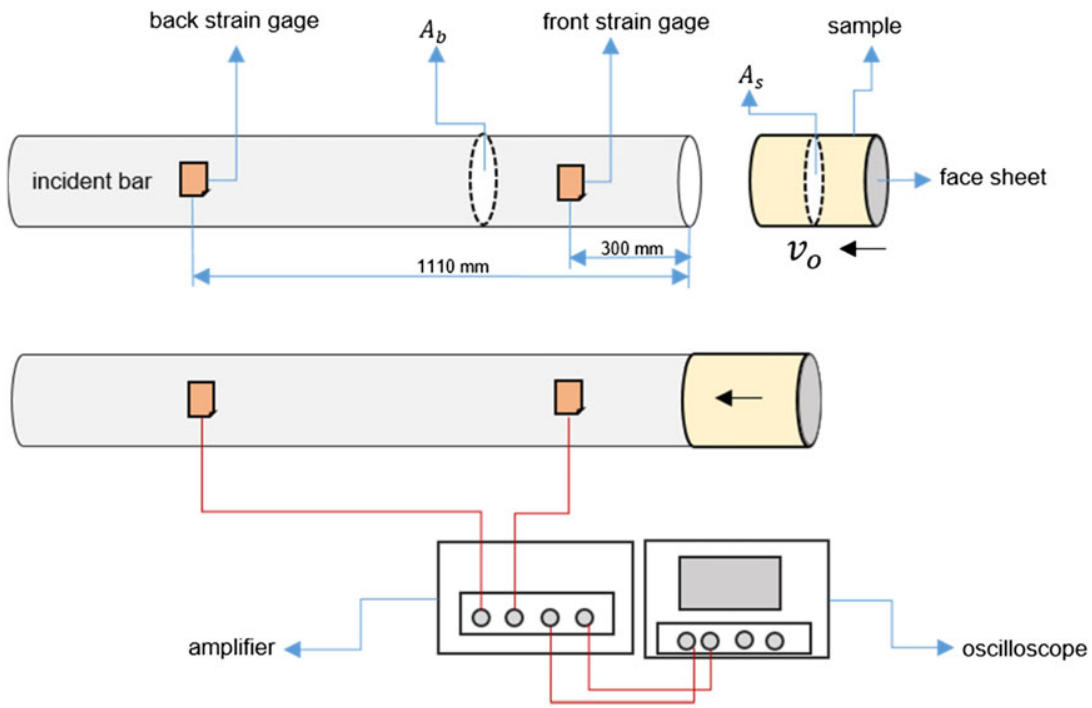
(a)

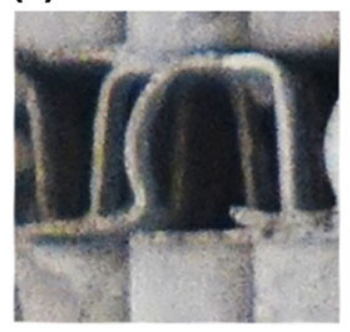

(b)

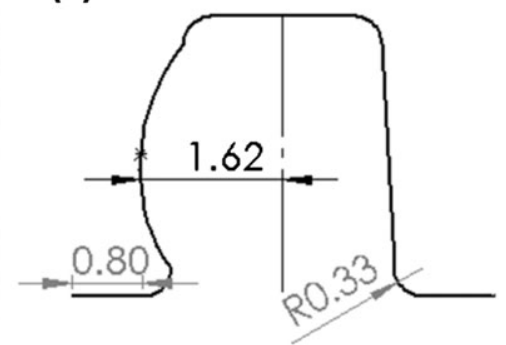

FIGURE 5 (a) Picture and (b) drawing of imperfect unit fin

\section{4 | NUMERICAL MODELS}

The sample models were constructed using perfect unit fin (Figure $2 b$ ) and imperfect fin shown in Figure 5a,b. The imperfect fin model was determined from a bent fin wall at the outer surface of a test sample as shown in Figure 5a. In the imperfect fin model, one of the walls of fins is bent with a radius of $1.62 \mathrm{~mm}$ (Figure 5b). Four numerical test sample models of the corrugated core were then investigated in the present study: (a) perfect model I (Figure 6a), (b) perfect model II (Figure 6b), (c) one-layer imperfect model (Figure 6c), and (d) two-layer imperfect model (Figure 6 d). In the perfect model I and perfect model II, all layers were constructed using the perfect unit fins (Figure 6a) and imperfect unit fins (Figure 6b), respectively. In the one-layer imperfect model, only the 10th layer (from the top to the bottom of sample, 15 layers) was constructed using the imperfect unit fins as shown by an arrow in Figure 6c, and in the two-layer imperfect model, the second and 10th layers were constructed using the imperfect unit fins as shown by arrows in Figure 6d. The perfect model I, perfect model II, and one-layer and two-layer imperfect models consisted of 34942, 41921, 35116, and 33570 shell elements, respectively.

The trapezoidal corrugated fin layers were meshed using $0.25 \times 0.25$-mm size Belytschko-Tsay shell elements with five integration points, whereas $1050 \mathrm{Al}$ face sheets using the constant stress solid elements. In order to increase the accuracy of models, the number of integration points should be higher than two when buckling is the dominant deformation mode. ${ }^{[43]}$ The material model for $1050 \mathrm{Al}$ alloy was MAT_SIMPLIFIED_JOHNSON_COOK (Material type 98). Material type 98 does not take into account temperature effect, and the strain rate effect is also exluded because $\mathrm{Al}$ alloys have negligible strain rate-dependent flow stress. The material model parameters of $1050 \mathrm{H} 14 \mathrm{Al}$ were determined $^{[40]}$ previously as $\mathrm{A}=102 \mathrm{MPa}, \mathrm{B}=98 \mathrm{MPa}$, and $n=0.18$.

The quasi-static compression test model consisted of the top and bottom compression test steel platen and sample. Each compression test platen was modelled using 38,400 constant stress solid elements. Because the total CPU time for the quasi-static test solutions was relatively long, ${ }^{[44]}$ the mass scaling was applied in the quasi-static simulations. The mass was added or removed from elements so that the time step of the elements was the same. In order to determine the mass scaling factor, the simulation was initially run without mass scaling and the determined time step without mass scaling was multiplied by 10,100 , and 1,000. It was found numerically that the kinetic energy change was substantially lower than the internal energy change when the mass scaling factor was 1,000.

(a)

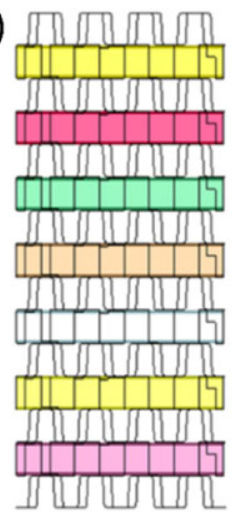

(b)

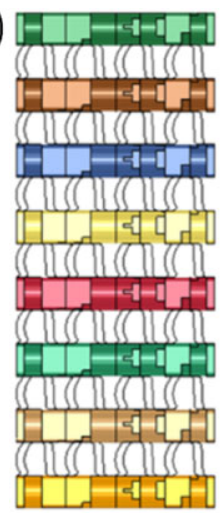

(c)

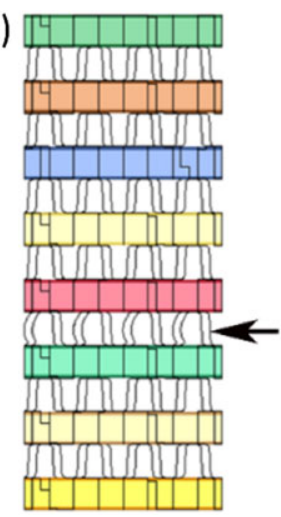

(d)

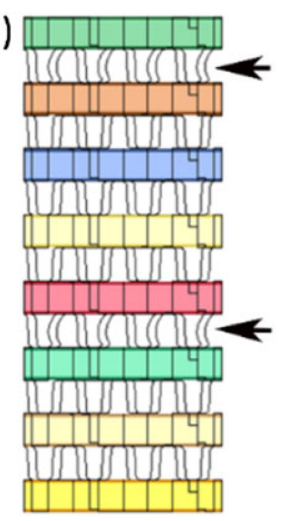

FIGURE 6 (a) The perfect model I, (b) the perfect model II, (c) one-layer imperfect model, and (d) the two-layer imperfect sample model 
(a)

(b)
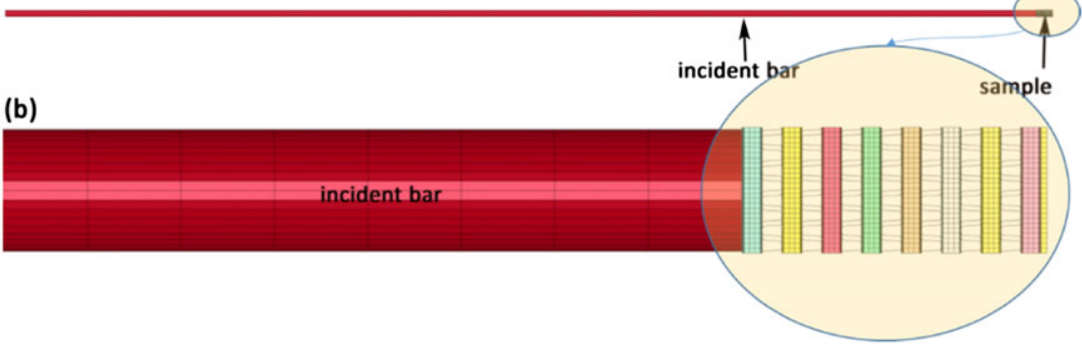

FIGURE 7 (a) Taylor impact test model and (b) specimen bar interfaces

The pictures of full impact test model and sample-incident bar interface are shown in Figure 7a,b. In the model, the impact velocity was defined to the mass by VELOCITY_GENERATION card in LS-DYNA. The numerical impact velocities were 135, 150, and $200 \mathrm{~m} / \mathrm{s}$, the same as the tests. The contact between incident bar and sample was defined by AUTOMATIC_SURFACE_TO SURFACE contact. The contacts between the fin layers and fin layer and face sheet were defined by AUTOMATIC_SINGLE_SURFACE contact algorithm. The Inconel 718 incident bar was modelled using MAT01_ELASTIC material model with $E=204 \mathrm{GPa}, v=0.29$, and $\rho=8,393 \mathrm{~kg} / \mathrm{m}^{3}$. The static and dynamic friction coefficients were set sequentially to 0.3 and 0.2 in all contact definitions. These values of friction coefficients were also previously applied and shown to yield the numerical results well agreed with the experiments. ${ }^{[41,45,46]}$ The numerical stresses on the incident bar were calculated at the same locations with the strain gages in the experimental set-up. The further details of the quasi-static compression and impact test models are given elsewhere. ${ }^{[7]}$

\section{5 | RESULTS AND DISCUSSIONS}

\section{1 | Quasi-static tests and models}

The quasi-static compression stress-strain and mean stress-strain curves of tests (representative of three tests) and models are shown in Figure 8a and b. In the insets of the same figures, the deformation pictures of the test and models at $0.2,0.4,0.6$, and 0.8 strains are shown for comparison. The quasi-static compression tests of corrugated core show, as similar with other metallic cellular structures such as aluminium foams and honeycombs, three sequential deformation regions of elastic, plateau, and densification. ${ }^{[47]}$ The initial crushing stress is determined as the average of three tests and the plateau stress is the average of three mean crushing stresses $\left(\sigma_{m}=\frac{\int \sigma d \varepsilon}{\varepsilon}\right)$ at 0.4 strain. The quasi-static densification strains are determined by the intercept method ${ }^{[47]}$ in which a tangent line is drawn to the densification part of the

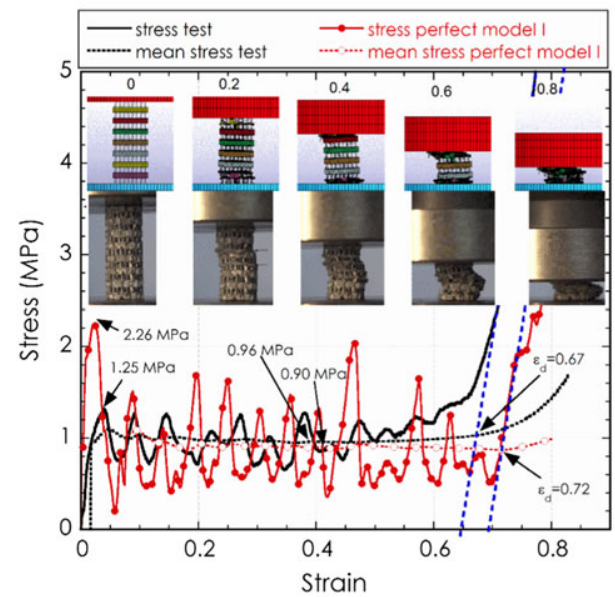

(a)

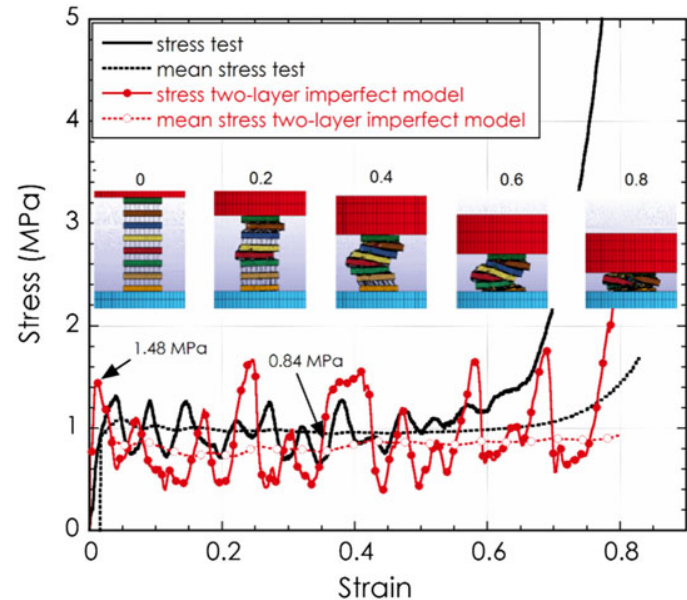

(b)

FIGURE 8 The quasi-static stress-strain and mean stress-strain curves of a test and (a) perfect model I and (b) two-layer imperfect model and the pictures of the deformed sample at 0-0.8 strain 
TABLE 1 The initial peak stresses and densification strains of the tests and models at different velocities

\begin{tabular}{|c|c|c|c|c|c|c|c|c|}
\hline Velocity & \multicolumn{2}{|l|}{$0.0048 \mathrm{~m} \mathrm{~s}^{-1}$} & \multicolumn{2}{|l|}{$135 \mathrm{~m} \mathrm{~s}^{-1}$} & \multicolumn{2}{|l|}{$150 \mathrm{~m} \mathrm{~s}^{-1}$} & \multicolumn{2}{|l|}{$200 \mathrm{~m} \mathrm{~s}^{-1}$} \\
\hline Test & $1.25 \mp 0.06$ & 0.67 & $7.8 \mp 0.2$ & 0.69 & $10.5 \mp 0.3$ & 0.75 & $13.8 \mp 0.3$ & 0.81 \\
\hline Perfect I model & 2.26 & 0.72 & 12.9 & 0.81 & 13.8 & 0.84 & 20.8 & 0.88 \\
\hline Perfect II model & 1.52 & 0.72 & 10.8 & 0.81 & 12.0 & 0.84 & 19.8 & 0.88 \\
\hline Two-layer imperfect model & 1.48 & 0.72 & 12.8 & 0.81 & 13.8 & 0.84 & 19.2 & 0.88 \\
\hline
\end{tabular}

stress-strain curve, and the intercept of this line with the mean crushing stress is taken as the densification strain. The quasi-static initial crushing and mean stresses determined by the above methods are further shown in Figure 8a and $b$ by arrows. As noted in the same figures, the investigated quasi-static sample models result in higher initial crushing stresses than the tests $(1.25 \mathrm{MPa})$, whereas the mean crushing stress of the tests $(0.96 \mathrm{MPa})$ is higher than those of the models. The insertion of one imperfect layer decreases the initial crushing stress of the perfect model I from

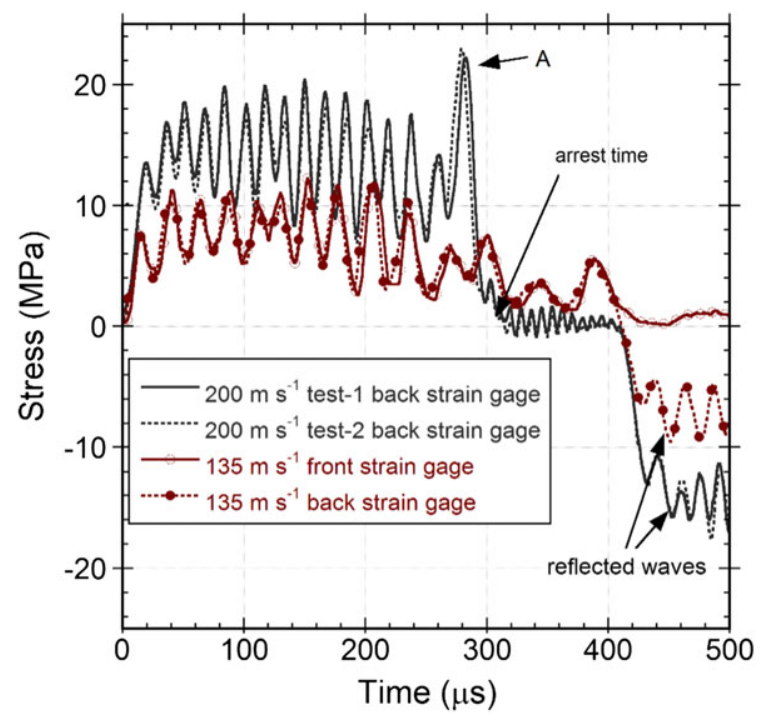

(a)

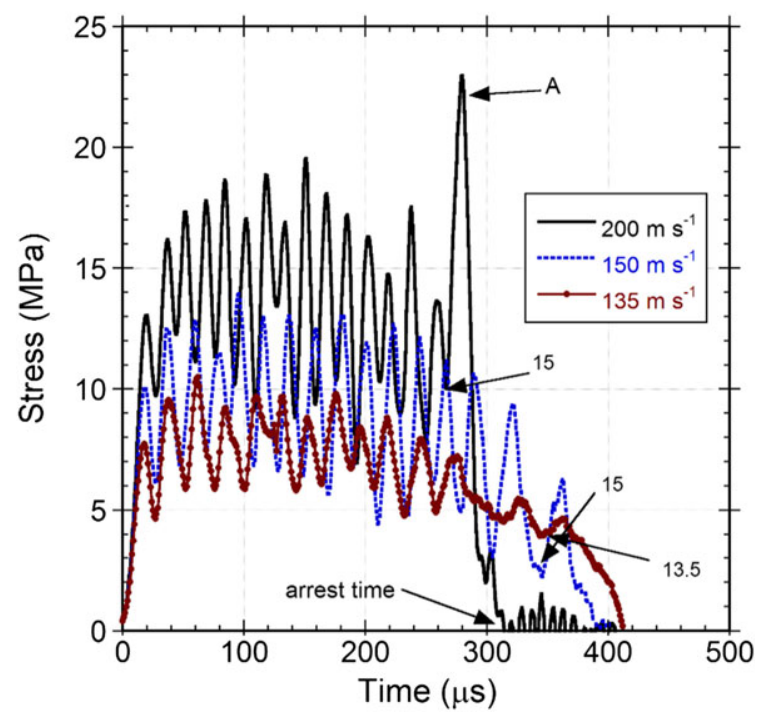

(b)

FIGURE 9 The stress-time histories of (a) two tests (back gage stress) at $200 \mathrm{~m} / \mathrm{s}$ and front and back gage stress at $135 \mathrm{~m} / \mathrm{s}$ and (b) back gage stress at 135, 150, and $200 \mathrm{~m} / \mathrm{s}$ 
2.26 MPa (Figure 8a) to 1.61 MPa: the insertion of two imperfect layers to $1.48 \mathrm{MPa}$ (Figure 8d) and the insertion of 15 imperfect layers to $1.52 \mathrm{MPa}$. The mean crushing stress also decreases from $0.90 \mathrm{MPa}$ in the perfect model I to $0.83,0.86$ and $0.88 \mathrm{MPa}$ in the perfect model II and one- and two-layer imperfect models, respectively. The insertion of imperfect layer (s) tends to decrease both initial crushing and mean stresses at the quasi-static velocity. Similar results of the reduced initial crushing and post peak and valley stresses with the insertion of imperfections were reported previously in testing metallic pyramidal truss and Nomex honeycomb core at quasi-static velocities. ${ }^{[48,49]}$ All models however result in nearly the same densification strain, 0.72 , which is higher than that of the tests, 0.67 (Figure 8a). The lower experimental densification strain is ascribed to the filler accumulation at the layer contacts (Figure 3b), leading to increased wall thicknesses at these regions. The effect of thicker cell walls will be addressed in another study and therefore is not taken into account in the present study.

Experimentally, the initial layer crushing/crush banding starts at the weakest fin layer, preferentially in a layer interior of the sample (Figure 8a). The crush band progresses discretely with the crushing of individual layers or simultaneously two or more layers. It is also noted that the collapse of midsection layers occurs at the later stages of deformation, which leads to the bending of the test sample at increasing strains (Figure 8a). Although not shown here, the similar bending of the test sample at a larger sample diameter $(40 \mathrm{~mm})$ and shorter sample lengths $(28.8$ and $19.2 \mathrm{~mm}$ ) was also observed in quasi-static tests. ${ }^{[7]}$ Layer crushing in the perfect model I starts at the layers near the ends of sample and progresses sequentially to the midsection layers (Figure 8a). The layer crushing in the one- and two-imperfect layer models always starts at the imperfect layers, 10th and 2nd, and progresses discretely to the uncrushed parts (Figure $8 \mathrm{~b}$ ). The imperfect models give rise to similar sample's bending with the tests. The insertions of imperfect layers are effective in reducing initial crushing and mean stresses, whereas the densification strain is not significantly affected because the unit-fin sizes of the models are the same (Table 1). The reduced mean stresses in the imperfect models is partly ascribed to the change of the deformation mode relative to the perfect model $\mathrm{I}$. When both the initial and mean crushing stresses and the crush band initiation and progression are considered together, it may be concluded that the quasi-static deformation behaviour of the tested corrugated sample is better predicted by the imperfect models.

\subsection{Impact tests and models}

The experimental stress-time histories of the two samples tested at $200 \mathrm{~m} / \mathrm{s}$ as seen in Figure 9a are very much repeatable, despite small differences between the peak and valley stresses of the tests. Note that the developed compression shock stress in this and also the following figures is represented as tensile stress for convenience. The front and back strain gage experimental stress-time histories of a sample tested at $135 \mathrm{~m} / \mathrm{s}$ are also shown in the same figure. The stresses of both gages are seen to be nearly equal to each other, confirming a negligible stress wave dispersion on the incident bar. It is also noted in Figure 9a that the sample deformations are arrested at all velocities before the

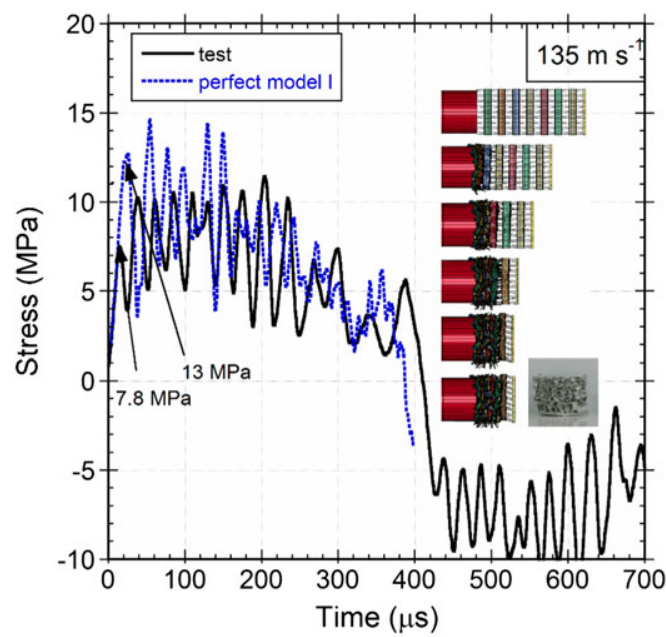

(a)

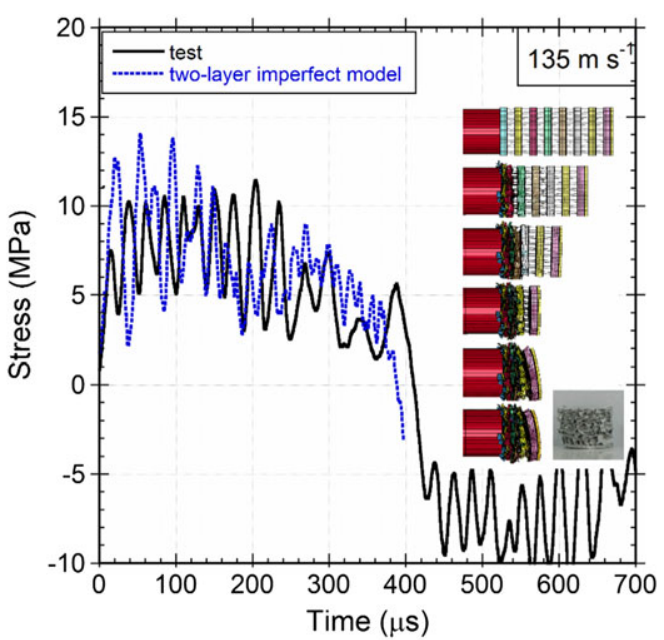

(b)

FIGURE 10 The stress vs time histories and deformed pictures (time interval is $100 \mu \mathrm{s}$ ) of the corrugated samples tested at $135 \mathrm{~m} / \mathrm{s}$ (a) perfect model I and (b) two layer imperfect model 
compressive wave returns back as tensile wave to the incident bar (reflected wave). The time at which the stress is reduced to zero is taken as the arrest time as shown in Figure 9a. Figure 9b shows the back strain gage experimental stress-time histories of the corrugate samples tested at 135, 150, and $200 \mathrm{~m} / \mathrm{s}$. The effect of increasing impact velocity is clearly seen in the same figure: the crushing stress increases and the arrest time decreases. At the highest velocity, $200 \mathrm{~m} / \mathrm{s}$, the sharp-rise in the experimental stress values near the arrest time as marked by arrow (A) in Figure $9 \mathrm{~b}$ is caused by the densification of the sample at this velocity. Furthermore, each stress valley in Figure 9b corresponds to the completion of the deformation/crushing of a single layer. There are sequentially total 15, 15, and 13.5 layer crushing in the tests at 200, 150, and $135 \mathrm{~m} / \mathrm{s}$ as shown by the arrows in Figure $9 \mathrm{~b}$. All layers are crushed at $150 \mathrm{~m} / \mathrm{s}$ with no deformation in the densification region, whereas the sample at $200 \mathrm{~m} / \mathrm{s}$ deforms partly in the densification region. The layer crushing is noted in Figure 10 to cease at $\sim 400 \mu \mathrm{s}$, which nearly corresponds to the arrest time in Figure 9 b. Although not shown here, similar shock wave progression and layer crushing were also recorded for the tests at 135 and $200 \mathrm{~m} / \mathrm{s}$. These records further confirmed that the shock deformation mode occurred at all impact velocities investigated.

\section{3 | Effect of imperfect layer and r-p-p-l model}

Figure 10a and $\mathrm{b}$ show sequentially the stress-time histories of the perfect model I, perfect model II, one-layer imperfect model, and two-layer imperfect model at $135 \mathrm{~m} / \mathrm{s}$ together with that of the test. In the same figures, the experimental

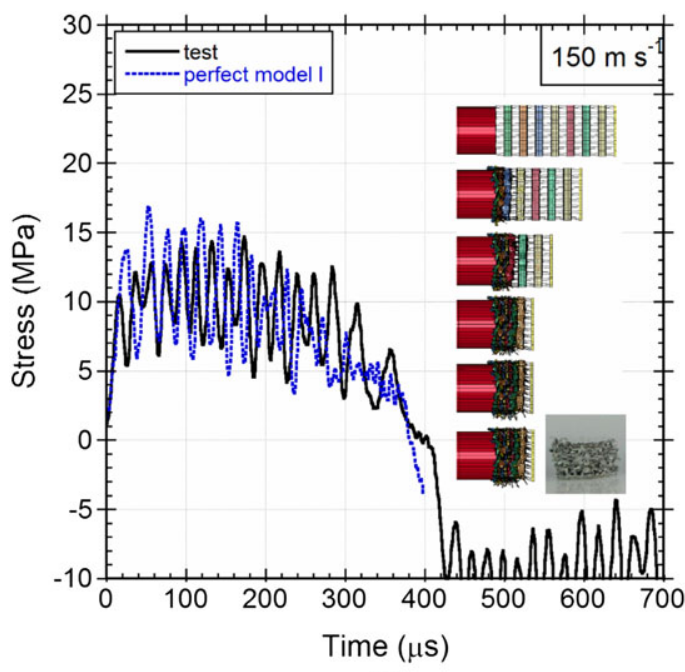

(a)

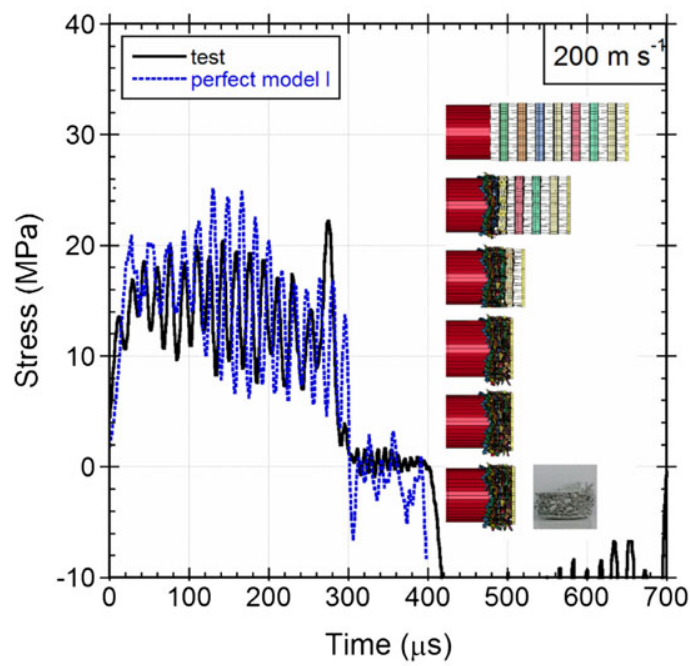

(c)

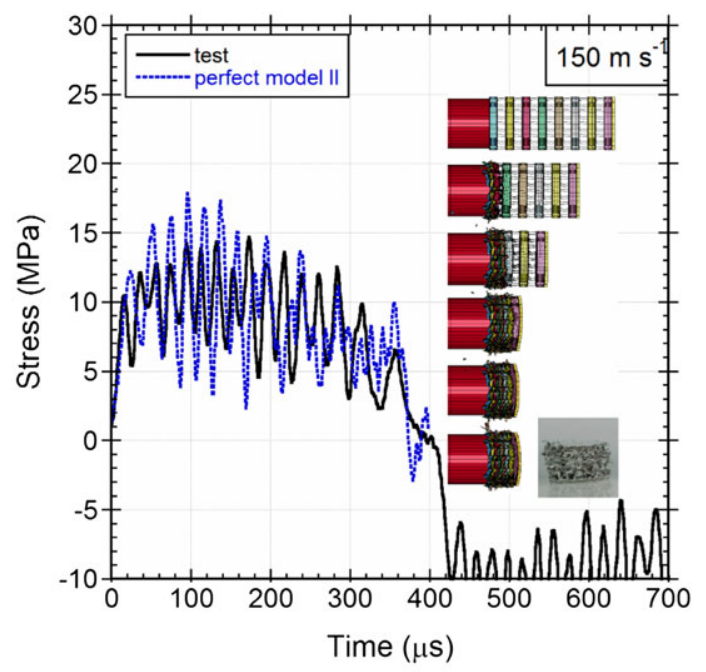

(b)

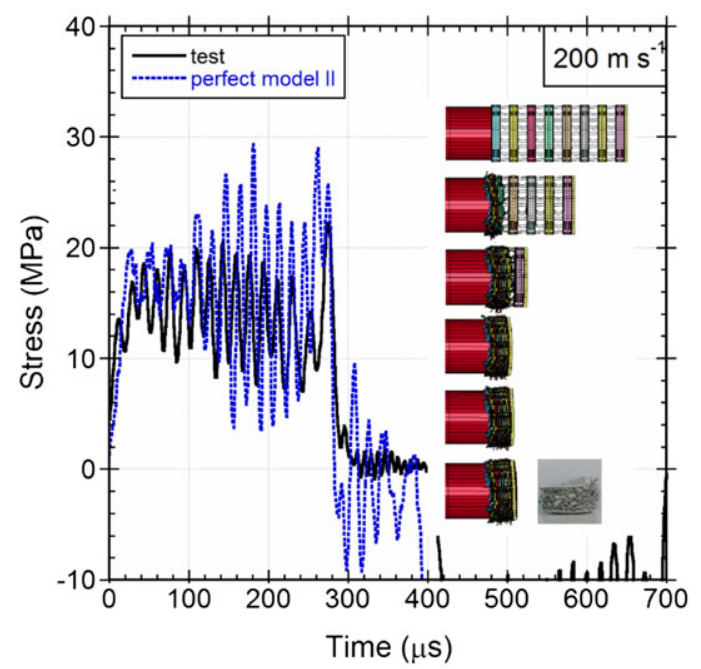

(d)

FIGURE 11 The stress vs time histories and deformed pictures (time interval is $100 \mu \mathrm{s}$ ) of the corrugated samples tested at $150 \mathrm{~m} / \mathrm{s}$ (a) perfect model I and (b) perfect model II and $200 \mathrm{~m} / \mathrm{s}$ (c) perfect model I and (d) perfect model II 
final deformed picture of the test sample and the sequential deformation pictures of the model samples until about the arrest times are also shown for comparison. The perfect model I and one- and two-layer imperfect models show almost the same initial peak stress, $13 \mathrm{MPa}$, higher than that of the test, $7.8 \mathrm{MPa}$, whereas the perfect model II shows relatively lower initial crushing stress, $\sim 11 \mathrm{MPa}$ (Figure 10b and Table 1). Because the impact end layer, the first layer, is a free surface layer and the initial collapse starts at that layer, the experimental and numerical initial peak stresses associated with the first layer are lower than the following peak stresses. Also, the gradual reduction of the stress values near the arrest time is due to the decrease of impact velocity with time. The experimental arrest time is noted to be best approximated by the perfect model II (Figure 10b). Figures 11(a) and (b) show the perfect model I and perfect model II stress-time histories together with that of the test at $150 \mathrm{~m} / \mathrm{s}$, respectively. The differences in the initial peak stresses between the perfect model I and II and the test decrease at $150 \mathrm{~m} / \mathrm{s}$, and the initial peak stresses are 13.8, 12, and 10.5 $\mathrm{MPa}$ for the perfect model I, perfect model II, and test, respectively. When the impact velocity increases to $200 \mathrm{~m} / \mathrm{s}$, all layers are fully compacted in both models as shown in the insets of Figures 11(c) and (d). It is noted that the experimental stress-rise at the end of the stress-time graph is not seen in the perfect model I (Figure 11c), whereas the perfect model II shows slight increase in the stress near the arrest time (Figure 11d). The experimental and numerical final thicknesses of the samples tested at three velocities are further listed in Table 2. It is seen in this table that the experimental final thicknesses of the test samples and hence the densification strains (Table 1) are nearly approached by the perfect model II at all velocities and by the perfect model I at $200 \mathrm{~m} / \mathrm{s}$.

The layer and nominal strain-time and stress-time histories of the two-layer imperfect model at quasi-static, 135, 150, and $200 \mathrm{~m} / \mathrm{s}$, are shown sequentially in Figure 12a-d. The velocity-time histories of the models are also shown in Figure 12b-d. The quasi-static localised deformation in the two-layer imperfect model starts at the 10th layer (imperfect layer) and ninth layer and proceeds with the crushing of the second (imperfect layer) and the first layer as seen in Figure 12a. Initially, layers are compressed until about 0.4 strain, then these crushed layers are further compressed until about the densification strain either gradually or step-wise. However, the layer crushing at 135 and $150 \mathrm{~m} / \mathrm{s}$ velocity is sequential starting at the first layer, except the 10th and ninth layers crush together until about the strains above the densification strain (Figure 12b-c). But the layer crushing is completely sequential at $200 \mathrm{~m} / \mathrm{s}$ (Figure 12d). The densification strains in the models were determined from the final strains of the first three layers in Figure 12c-d, in which the decrease in the initial velocity is not much significant. The densification strains of the two-layer imperfect model are sequentially $0.81,0.84$, and 0.88 at 135, 150, and $200 \mathrm{~m} / \mathrm{s}$, as shown in Figure 12b- $\mathrm{d}$ and tabulated in Table 1 . The final nominal strains are also shown in the same figures and $0.73,0.76$, and 0.85 at 135,150 , and $200 \mathrm{~m} / \mathrm{s}$, respectively. Although not shown here, the layer strain-time history of the one-layer imperfect model was also very similar to that of the two-layer imperfect model.

Layer and nominal strain-time and stress-time histories of the perfect model II at quasi-static, 135, 150, and $200 \mathrm{~m} / \mathrm{s}$ are shown sequentially in Figure 13a and b. The initial crushing in quasi-static compression in perfect model II localised the layers near the specimen's ends: Initially, the second and third layers collapse and thereafter the 14th and 13th layers as seen in Figure 13a. The layer crushing occurs individually and more or less sequentially/gradually starting both at the top and bottom layers until about or slightly below the densification strain. It is further noted that the step-wise layer compression at quasi-static velocity is seen in the perfect models only for few layers, although it is a dominant deformation mode in the imperfect models. The layer crushing in the perfect model II is thoroughly sequential at 135, 150, and $200 \mathrm{~m} / \mathrm{s}$ as seen in Figure 13b. The densification strains of the perfect model II are the same as the densification strains of two-layer imperfect model as seen in Figure 13b, whereas the final nominal strains are higher and are $0.75,0.79$, and 0.88 at 135, 150, and $200 \mathrm{~m} / \mathrm{s}$, respectively. The higher final nominal strains in the perfect model II as compared with the imperfect models are attributed to the geometrically soft structure due to its all bent fin wall layers leading to deformations until about larger strains.

The numerical layer strain-time histories and the pictures of the recovered samples impacted at $135 \mathrm{~m} / \mathrm{s}$ in the perfect model I and II and two-layer imperfect model show that the last layer, the layer 15th, deforms elastically, and the

TABLE 2 The experimental and numerical final thickness of the tested corrugated sample at different velocities

\begin{tabular}{|c|c|c|c|}
\hline Velocity & $135 \mathrm{~m} \mathrm{~s}^{-1}$ & $150 \mathrm{~m} \mathrm{~s}^{-1}$ & $200 \mathrm{~m} \mathrm{~s}^{-1}$ \\
\hline Experimental thickness (mm) & 14.78 & 11.16 & 8.97 \\
\hline Perfect I model thickness (mm) & 16.20 & 14.9 & 9.0 \\
\hline Perfect II model thickness (mm) & 13.7 & 11.5 & 8.8 \\
\hline
\end{tabular}




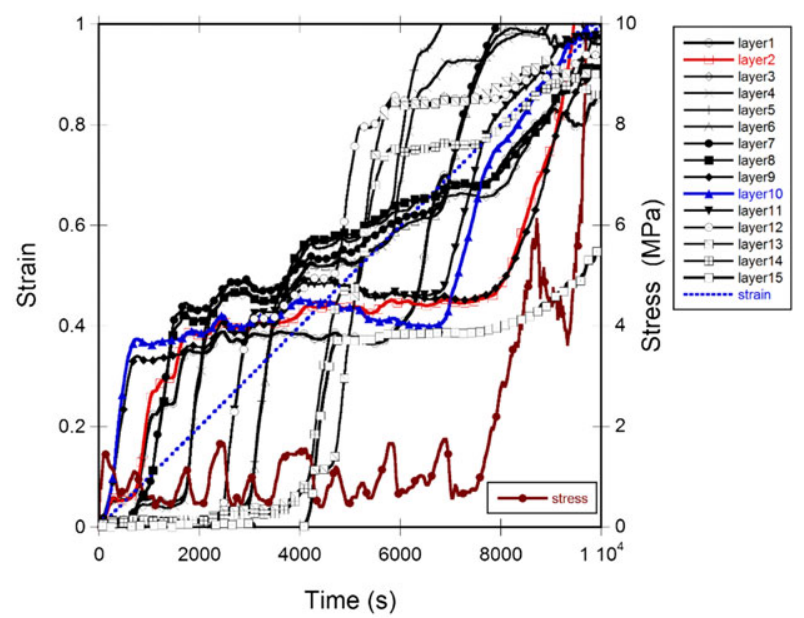

(a)

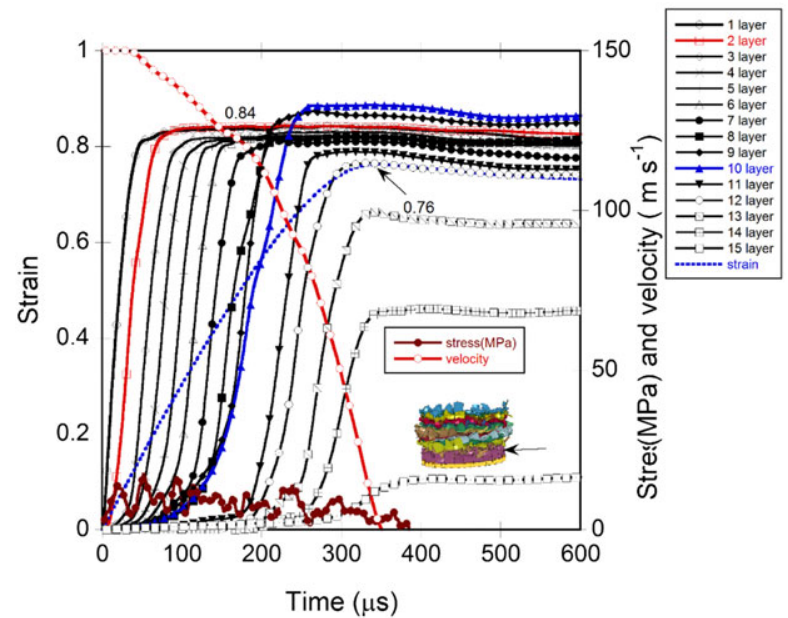

(c)

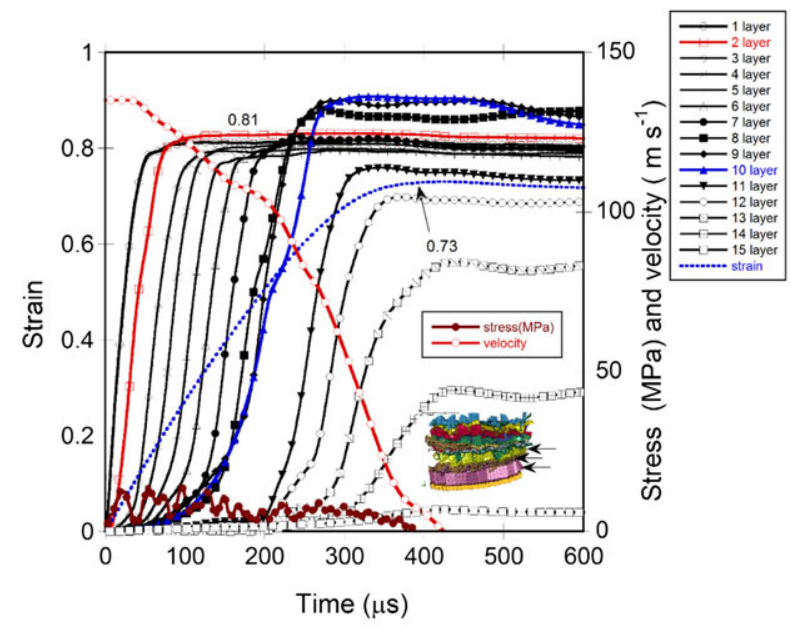

(b)

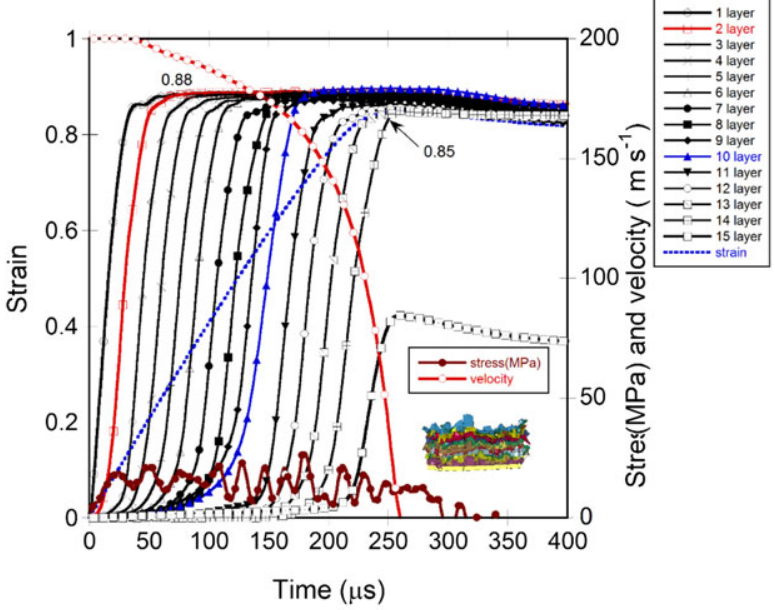

(d)

FIGURE 12 Layer strain-time, strain-time and stress-time graphs of two layer imperfect model at (a) 0.0048, (b) 135, (c) 150 and (d) $200 \mathrm{~m} / \mathrm{s}$

layer strains are below the densification strain between 11th and 14th layers. When the velocity increases to $150 \mathrm{~m} / \mathrm{s}$, the layer strains between 11th and 15th layers relatively increase, but still the final strains are below the densification strain. Only the last layer is however compacted below the densification strain at $200 \mathrm{~m} / \mathrm{s}$. The layer strain-time

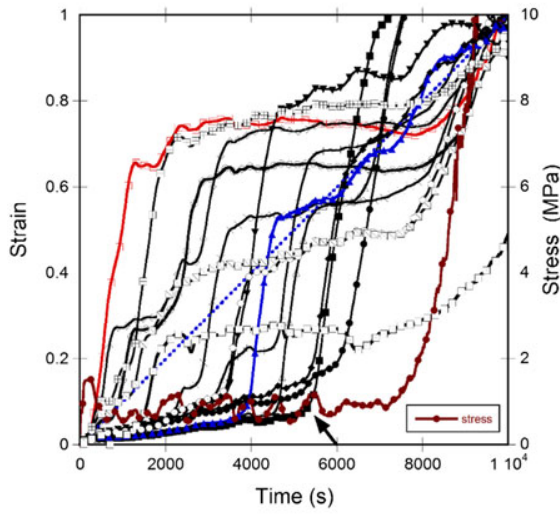

(a)

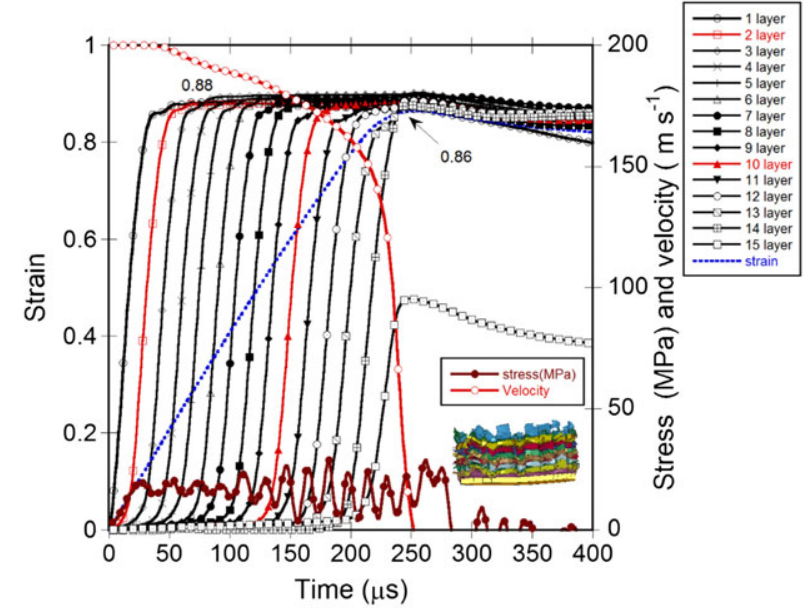

(b)

FIGURE 13 Layer strain-time, strain-time and stress-time graphs of perfect model II at (a) 0.0048 and (b) $200 \mathrm{~m} / \mathrm{s}$ 


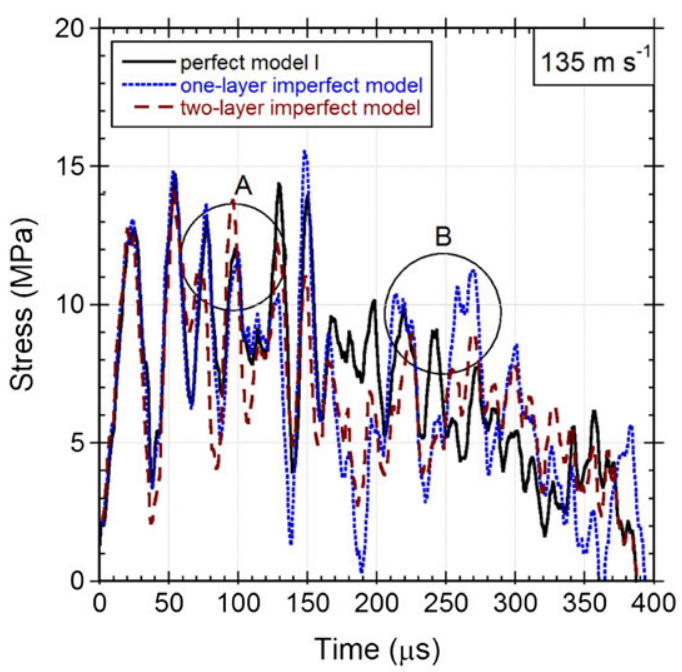

(a)

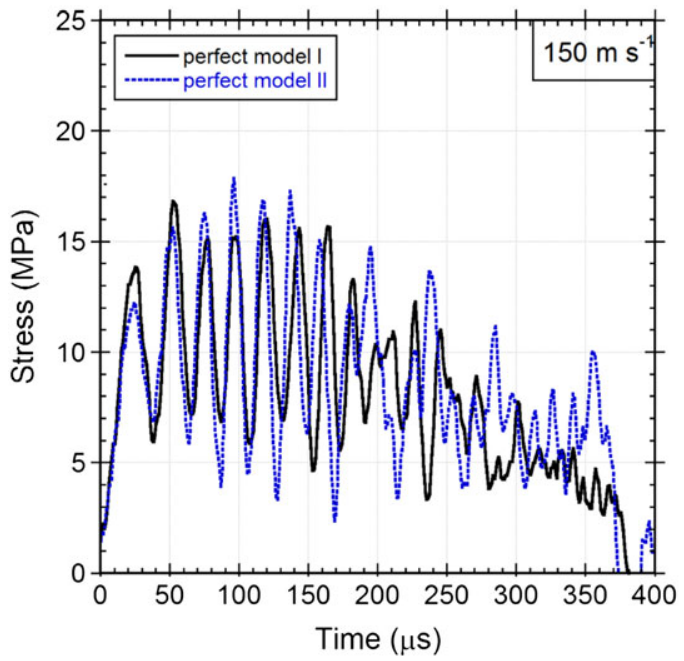

(c)

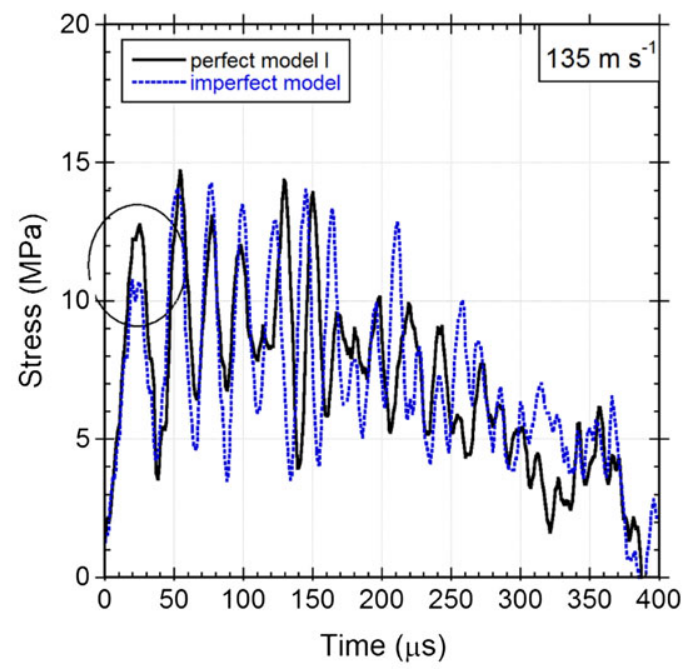

(b)

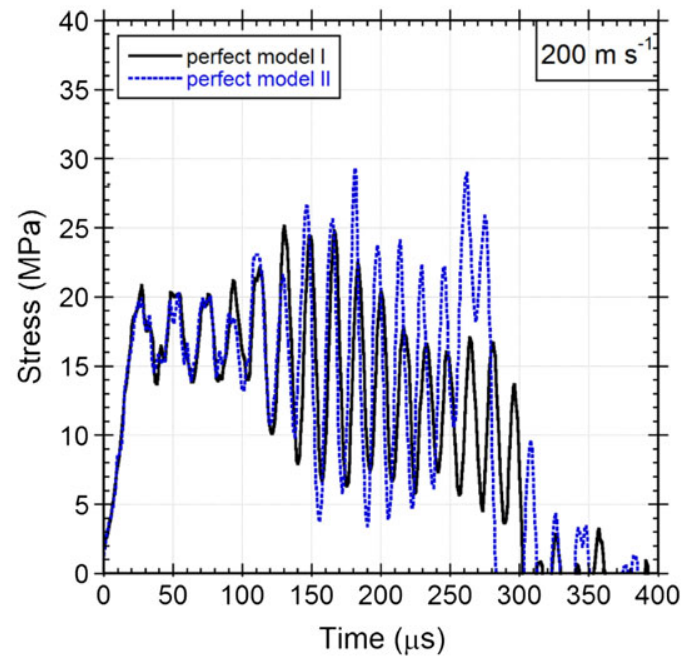

(d)

FIGURE 14 Stress-time curves (a) Perfect model I and imperfect models and (b) Perfect model I and II at $135 \mathrm{~m} / \mathrm{s}$ and stress time curves of perfect model I and II at (c) $150 \mathrm{~m} / \mathrm{s}$ and (d) $200 \mathrm{~m} / \mathrm{s}$

histories and pictures of recovered samples of the perfect model II show that the last and 14th layers are partially compacted below the densification strain at $135 \mathrm{~m} / \mathrm{s}$; only the last layer is partially compacted below the densification strain at 150 and $200 \mathrm{~m} / \mathrm{s}$; the compaction strain of the last layer is higher at $200 \mathrm{~m} / \mathrm{s}$. However, the samples experimentally tested at $200 \mathrm{~m} / \mathrm{s}$ are fully compacted to the densification strain.

The following equation was proposed to calculate the critical velocity for the shock formation by considering that all the internal energy was due to the loss of the kinetic energy. ${ }^{[15]}$

$$
v_{c r}=\sqrt{\frac{2 \sigma_{p} \varepsilon_{d}}{\rho_{o}}} .
$$

Taking $\sigma_{p}=0.96 \mathrm{MPa}$ (the quasi-static experimental mean stress), $\sigma_{\mathrm{cr}}=0.7 \mathrm{MPa}, \rho_{o}=326 \mathrm{~kg} / \mathrm{m}^{3}$, and $\varepsilon_{d}=0.72$ (numerical quasi-static densification strain), the critical velocity is calculated $\sim 65 \mathrm{~m} / \mathrm{s}$. The initial impact velocities investigated in present study are therefore higher than the critical velocity for shock formation.

The energy absorbing structures are classified as Type I and Type II. ${ }^{[50]}$ Type I structures show a flat-topped loaddisplacement curve, whereas Type II structures exhibit an initial peak-load followed by a sharp decline. The propagation of the plastic wave at high strain rates suppresses the more compliant bending modes and hence increases the crushing 
stress. ${ }^{[51]}$ The inertial effects associated with the shock formation were reported to be responsible for the stress enchantment above the critical velocity, whereas the micro inertial effects were ascribed to the stress enchantment below the critical velocity in cellular structures. ${ }^{[1,3,52]}$ The micro inertial effects on the stress enhancement were reported to be relatively weak especially in the high velocity regime where the inertial effects associated with the shock formation were dominant. ${ }^{[1,27]}$

In the shock mode velocity range, the effect of imperfect layers on the shock stress-time histories at $135 \mathrm{~m} / \mathrm{s}$ is shown in Figure 14a. The insertion of imperfect layer does not affect the initial peak stress and the peak stress values until about the imperfect layers start to collapse. Note that the imperfect layer crushing is marked by the circles in Figure 14a for the one and two-layer imperfect models. The circle A corresponds to the crushing of the second layer and the circle B to the crushing of the 10th layer. As seen in the same figure, in the event of the imperfect layer crushing, the peak stress values increase, whereas the valley stress values decrease as compared with those of the perfect model I. The compaction of the imperfect layers over the densification strain leads to higher peak stress values. The effect of insertion of fully imperfect layers (the perfect model II) is shown in Figure 14b-d at 135, 150, and $200 \mathrm{~m} / \mathrm{s}$. The perfect model I shows higher initial peak and valley stresses than the perfect model II at 135 and $150 \mathrm{~m} / \mathrm{s}$, but

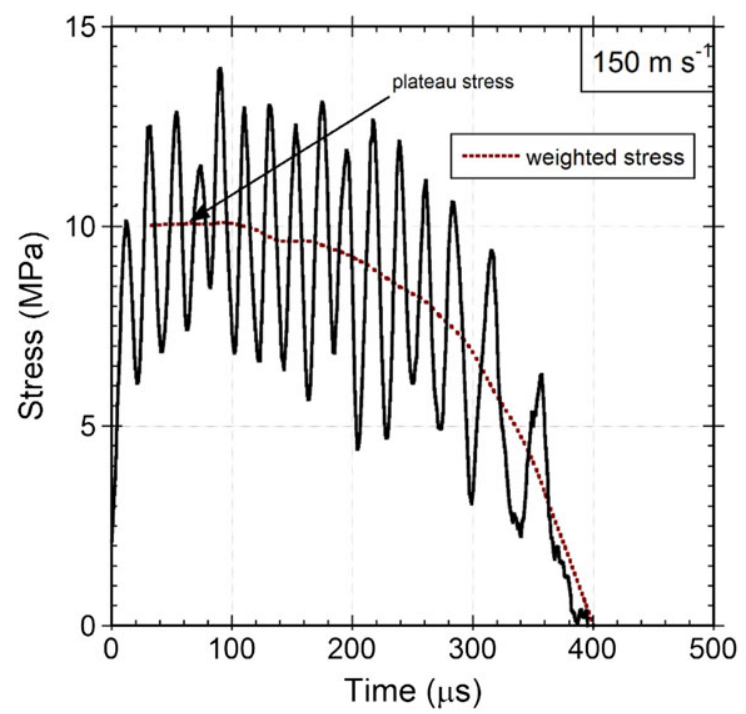

(a)

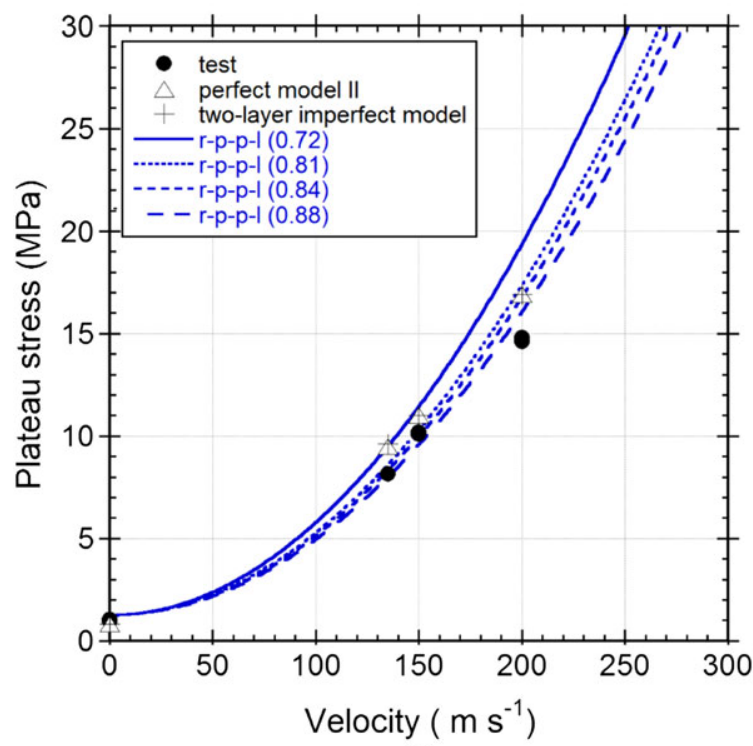

(b)

FIGURE 15 (a) stress vs. time graph showing the plateau stress determination and (b) the variation of the plateau stress of the tests, models and r-p-p-1 model with velocity 
the effect disappears when the velocity increases to $200 \mathrm{~m} / \mathrm{s}$; both models show similar initial crushing stresses (Figure 14d). The critical velocity for the densification with a 1-mm back-thin face sheet layer was calculated using Equation (6) and the following material parameters: $\sigma_{\mathrm{p}}=0.96 \mathrm{MPa}$ and $\varepsilon_{\mathrm{d}}=0.72$ and 0.88 . With these values, the critical velocity varies between 90 and $100 \mathrm{~m} / \mathrm{s}$. The lack of a densification region in the numerical stress-time histories at 135,150 , and $200 \mathrm{~m} / \mathrm{s}$ is simply partly due to the reduction of the velocity of the sample during the course of the deformation. The observed experimental densification at $200 \mathrm{~m} / \mathrm{s}$ impact test is partly due to the thicker contact regions leading to early densification in real samples, partly due to the nonaxial impact of the samples to the end of the incident bar and partly due to the possible decrease of $\mathrm{Al}$ alloy during brazing.

In order to compare the peak stresses predicted by the r-p-p-l model, experiments, and the perfect and imperfect models, the mean crushing stresses (plateau stress) of the experiments and models were determined. The first initial peak stress associated with crushing of the first layer is excluded in the determination of plateau stress. Figure 15a shows the experimental stress-time graph at $150 \mathrm{~m} / \mathrm{s}$ with the weighted plateau stress (dotted line). The plateau stress is determined at the flat part of the plateau stress corresponding to the collapses of the first three layers excluding the first layer. The variation of the experimental and model plateau stresses with the impact velocity is shown in Figure 15b. In the same figure, the classical r-p-p-l model predictions with quasi-static and dynamic densification strains are also shown. As seen in the same figure, the test and model plateau stresses show better predictions with the r-p-p-l model when the dynamic densification strains up to 0.88 are used in the calculations. The classical r-p-p-1 model however overestimates the initial peak stresses.

\section{6 | CONCLUSIONS}

The quasi-static compression and Taylor-like impact deformation of a layered 1050 H14 aluminium corrugated sandwich structure were determined both experimentally and numerically to investigate the effect of the insertion of imperfect layers on the shock mode of deformation. The quasi-static compression tests was performed at $0.0048 \mathrm{~m} / \mathrm{s}$ and impact tests at 135, 150, and $200 \mathrm{~m} / \mathrm{s}$. Three-dimensional finite element model of the tested specimens were developed using the LS-DYNA. The stress-time histories of the tests were verified by the simulations in the explicit finite element code of LS-DYNA. It was experimentally and numerically confirmed that the shock deformation mode occurred at all impact velocities investigated. The localised deformation in the quasi-static imperfect models of cylindrical sample started at the imperfect layers, the same as the experimental tests, and the layers were compressed until about the densification strain in a step-wise fashion. The localised deformation in the perfect models; however, started at the layers near the ends of sample and progressed sequentially to the midsection layers. The insertion of imperfect layer (s) also tended to decrease both initial crushing and mean stresses at the quasi-static velocity. In the shock mode, the sample crushed sequentially starting at the impact end layer regardless the perfect or imperfect models were used. The perfect and imperfect models resulted in similar initial crushing stresses in the shock mode. But the crushing of imperfect layers induced relatively high layer densification strains and peak strains and lower valley stresses. The layer strain histories revealed a velocity-dependent crushed layer densification strain, as the velocity increased layers compressed to higher strains. Both model types, the imperfect and perfect, however well approximated the stress-time histories and layer deformations of the shock mode. The r-p-p-l model based on the numerically determined densification strains also well predicted the plateau stresses of the shock mode.

\section{ACKNOWLEDGEMENT}

The authors would like to thank Cumhur Akar for providing corrugated aluminium samples.

\section{ORCID}

Mustafa Güden (D) http://orcid.org/0000-0001-6397-8418

\section{REFERENCES}

[1] P. J. Tan, S. R. Reid, J. J. Harrigan, Z. Zou, S. Li, J. Mech. Phys. Solids 2005, 53, 2174.

[2] Z. Zou, S. R. Reid, P. J. Tan, S. Li, J. J. Harrigan, Int. J. Impact Eng. 2009, 36, 165. 
[3] S. R. Reid, C. Peng, Int. J. Impact Eng. 1997, 19, 531.

[4] J. J. Harrigan, S. R. Reid, P. J. Tan, T. Y. Reddy, Int. J. Mech. Sci. 2005, 47, 521.

[5] A. Chen, H. Kim, R. J. Asaro, J. Bezares, Compos. Struct. 2011, 93, 2768.

[6] D. D. Radford, V. S. Deshpande, N. A. Fleck, Int. J. Impact Eng. 2005, 31, 1152.

[7] I. K. Odac, M. Guden, C. Klcaslan, A. Tasdemirci, Int. J. Impact Eng. 2017, 103, 64.

[8] P. W. Zhang, Z. H. Wang, L. M. Zhao, Appl. Phys A-Mater Sci Process 2017, 123, 11.

[9] S. L. Wang, Y. Y. Ding, C. F. Wang, Z. J. Zheng, J. L. Yu, Int. J. Impact Eng. 2017, 99, 111.

[10] H. Liu, Z. Q. Zhang, H. Liu, J. L. Yang, H. Lin, Compos Pt B-Eng 2017, 116, 76.

[11] B. Y. Zhang, Y. F. Lin, S. Li, D. X. Zhai, G. H. Wu, Compos Pt B-Eng. 2016, 98, 288.

[12] H. Liu, Z. Q. Zhang, H. Liu, J. L. Yang, Int. J. Impact Eng. 2016, 94, 109.

[13] V. S. Deshpande, N. A. Fleck, Int. J. Impact Eng. 2000, 24, 277.

[14] S. L. Lopatnikov, B. A. Gama, M. J. Haque, C. Krauthauser, J. W. Gillespie, M. Guden, I. W. Hall, Compos. Struct. $2003,61,61$.

[15] P. J. Tan, S. R. Reid, J. J. Harrigan, Z. Zou, S. Li, J. Mech. Phys. Solids 2005, 53, 2206.

[16] I. Elnasri, S. Pattofatto, H. Zhao, H. Tsitsiris, F. Hild, Y. Girard, J. Mech. Phys. Solids 2007, 55, 2652.

[17] H. Liu, Z. K. Cao, G. C. Yao, H. J. Luo, G. Y. Zu, Mater. Des. 2013, 47, 483.

[18] H. Zhao, G. Gary, Int. J. Impact Eng. 1998, 21, 827.

[19] D. H. Zhang, Q. G. Fei, P. W. Zhang, Thin-Walled Struct. 2017, 117, 199.

[20] J. X. Qiao, C. Q. Chen, Int. J. Solids Struct. 2016, 85-86, 57.

[21] Y. Tao, M. J. Chen, H. S. Chen, Y. M. Pei, D. N. Fang, Compos. Struct. 2015, 132, 644.

[22] S. F. Liao, Z. J. Zheng, J. L. Yu, Int. J. Impact Eng. 2013, 57, 7.

[23] Z. J. Zheng, J. L. Yu, J. R. Li, Int. J. Impact Eng. 2005, 32, 650.

[24] D. Ruan, G. Lu, B. Wang, T. X. Yu, Int. J. Impact Eng. 2003, 28, 161.

[25] Y. L. Sun, Q. M. Li, Int. J. Impact Eng. 2018, 112, 74.

[26] Z. J. Zheng, Y. D. Liu, J. L. Yu, S. R. Reid, Int. J. Impact Eng. 2012, 42, 66.

[27] Y. D. Liu, J. L. Yu, Z. J. Zheng, J. R. Li, Int. J. Solids Struct. 2009, 46, 3988.

[28] H. Kanahashi, T. Mukai, Y. Yamada, K. Shimojima, M. Mabuchi, T. G. Nieh, K. Higashi, Mater. Sci. Eng. A-Structural Materials Properties Microstructure and Processing 2000, 280, 349.

[29] J. L. Grenestedt, J. Mater. Sci. 2005, 40, 5853.

[30] K. Li, X. L. Gao, J. Wang, Int. J. Solids Struct. 2007, 44, 5003.

[31] X. C. Zhang, Y. Liu, B. Wang, Z. M. Zhang, Int J Mech Sci 2010, 52, 1290.

[32] H. Kanahashi, T. Mukai, T. G. Nieh, T. Aizawa, K. Higashi, Mater. Trans. 2002, 43, 2548.

[33] Y. Feng, Z. G. Zhu, S. H. Hu, Y. Pan, J. Mater. Sci. Technol. 2002, 18, 395.

[34] B. T. Cao, B. Hou, H. Zhao, Y. L. Li, J. G. Liu, Int. J. Impact Eng. 2018, 113, 98.

[35] B. T. Cao, B. Hou, H. Zhao, Int. J. Solids Struct. 2017, 109, 33.

[36] W. Huang, W. Zhang, X. L. Huang, X. W. Jiang, Y. Li, L. Zhang, Int. J. Impact Eng. 2017, 109, 78.

[37] P. Zhang, Y. S Cheng, J. Liu, Y. Li, C. Z. Zhang, H. L. Hou, C. M. Wang, Compos Pt B-Eng. 2016, $109,67$.

[38] G. Bartolozzi, N. Baldanzini, M. Pierini, G. Zonfrillo, Compos. Struct. 2015, 125, 343.

[39] C. Kılıçaslan, İ. K. Odacı, M. Güden, J. Sandw. Struct. Mater. 2016, 18, 667

[40] C. Kılıçaslan, M. Güden, İ. K. Odacı, A. Taşdemirci, Mater. Des. 2013, 46, 121.

[41] C. Kilicaslan, M. Guden, I. K. Odaci, A. Tasdemirci, Thin-Walled Struct. 2014, 78, 70.

[42] I. K. Odaci, C. Kilicaslan, A. Tasdemirci, M. Guden, Int. J. Crashworthiness 2012, 17, 508.

[43] R. Gumruk, S. Karadeniz, Thin-Walled Struct. 2008, 46, 1094.

[44] S. P. Santosa, T. Wierzbicki, A. G. Hanssen, M. Langseth, Int. J. Impact Eng. 2000, 24, 509.

[45] C. Kilicaslan, Thin-Walled Struct. 2015, 96, 82.

[46] C. Kilicaslan, I. K. Odaci, A. Tasdemirci, M. Guden, Strain 2014, 50, 236.

[47] L. Gibson, M. F. Ashby, Cellular solids: Structure and properties, Cambridge University Press, Cambridge 1997.

[48] S. Lee, F. Barthelat, J. W. Hutchinson, H. D. Espinosa, Int. J. Plast. 2006, 22, 2118. 
[49] S. Heimbs, Comput. Mater. Sci. 2009, 45, 205.

[50] C. R. Calladine, R. W. English, Int. J. Mech. Sci. 1984, 26, 689.

[51] D. G. Vaughn, J. M. Canning, J. W. Hutchinson, J Appl Mech-Trans ASME 2005, 72, 139.

[52] J. J. Harrigan, S. R. Reid, C. Peng, Int. J. Impact Eng. 1999, 22, 955.

How to cite this article: Sarıkaya M, Taşdemirci A, Güden M. Impact loading and modelling a multilayer aluminium corrugated/fin core: The effect of the insertion of imperfect fin layers. Strain. 2019;55:e12298. https:// doi.org/10.1111/str.12298 